University of South Carolina

Scholar Commons

4-2005

\title{
Comparisons Between Rail-Trail Users and Nonusers and Men and Women's Patterns of Use in a Suburban Community
}

Philip J. Troped

Ruth P. Saunders

Russell R. Pate

University of South Carolina - Columbia, rpate@mailbox.sc.edu

Follow this and additional works at: https://scholarcommons.sc.edu/

sph_physical_activity_public_health_facpub

Part of the Public Health Commons

\section{Publication Info}

Published in Journal of Physical Activity and Health, Volume 2, Issue 2, 2005, pages 169-180.

Troped, P. J., Saunders, R. P., \& Pate, R. R. (2005). Comparisons between rail-trail users and nonusers and men and women's patterns of use in a suburban community. Journal of Physical Activity and Health, 2(2), 169-180.

(c) Journal of Physical Activity and Health, 2005, Human Kinetics

This Article is brought to you by the Physical Activity and Public Health at Scholar Commons. It has been accepted for inclusion in Faculty Publications by an authorized administrator of Scholar Commons. For more information, please contact digres@mailbox.sc.edu. 


\title{
Comparisons Between Rail-Trail Users and Nonusers and Men and Women's Patterns of Use in a Suburban Community
}

\author{
Philip J. Troped, Ruth P. Saunders, and Russell R. Pate
}

Background: Physical activity research on trails is limited. We compared rail-trail users and nonusers on demographics, physical activity, and barriers/ concerns about trail use; and described use among men and women. Methods: Four hundred thirteen adults completed a physical activity survey during fall 1998. Chi-square statistics and $t$-tests were used to compare trail users to nonusers, and men and women on trail use. Results: More trail users (79\%) performed recreational physical activity $\geq 3 \mathrm{~d} / \mathrm{wk}$, compared to nonusers (47\%). Walking was the most common activity for trail users and nonusers. Both groups shared concerns about safe access to the trail and certain trail conditions. A higher percentage of female versus male users traveled to the trail by walking, walked on the trail, used the trail with a friend, and perceived that if the trail were not available their activity would decrease. Conclusions: Trail users perform more recreational physical activity than nonusers. Gender differences in trail use patterns should be considered in the design and promotion of trails.

Key Words: trails, environment, physical activity

The significant disease prevention and health promoting role of regular physical activity has been well established ${ }^{1}$ with physical activity identified as a leading health indicator. ${ }^{2}$ Since the 1990 s, there has been growing interest in using environmental strategies, such as building community trails, to promote physical activity. ${ }^{3-5}$ Paralleling this, there has been mounting scientific evidence that physical environmental characteristics of neighborhoods positively influence recreational ${ }^{6,7}$ and transportation-related physical activity. ${ }^{8}$

Several studies on trails and walking paths have appeared in the public health literature, ${ }^{9-13}$ supporting the case that trails are an important resource for physical activity promotion; for example, providing data indicating that rural walking

Troped is with the Harvard Prevention Research Center on Nutrition and Physical Activity, Dept of Society, Human Development and Health, Harvard School of Public Health, Boston, MA 02115. Saunders is with the Dept of Health Promotion, Education and Behavior, Arnold School of Public Health, University of South Carolina. Columbia, SC 29208. Pate is with the Dept of Exercise Science, Arnold School of Public Health, University of South Carolina, Columbia, SC 29208. 
paths help to support regular physical activity ${ }^{12}$ and for cost-effectiveness of trail development for increasing physical activity. ${ }^{13}$ In addition, peer-reviewed studies conducted in the academic fields of parks and recreation, leisure sciences, and urban planning have profiled trail users in different locales throughout the United States. ${ }^{14-18}$ Recent research in these disciplines has also provided objective data on levels of trail use utilizing devices, such as infrared counters. ${ }^{19}$ This body of nonpublic health research is a useful complement to physical activity studies in this area, informing researchers and practitioners about facility user characteristics and patterns of use in diverse areas of the country.

Most of the literature on community trails, however, has focused on facility users with little or no comparative information available about nonusers in local neighborhoods. From a physical activity promotion standpoint, it is important to understand sociodemographic and physical activity characteristics of both trail users and nonusers. These data can inform the design of strategies to encourage more community residents to use these resources. Also, trails are likely to be only part of the "environmental solution" for supporting and promoting physical activity in communities. Nonusers might be physically active, but at different venues such as walking on neighborhood sidewalks. Therefore, it is important to determine in a more integrated fashion how and where all residents of a community are active. Few physical activity studies we are aware of have examined trail users, as well as nonusers, from the perspective of the entire community in which a facility is located.

Another understudied area pertains to the differential role that trails could play for men and women. It is well established that patterns and determinants of physical activity differ between men and women. ${ }^{1}$ Available trail studies, however, have not examined gender differences in patterns of trail use. These data could be useful to those designing and constructing trails, as well as those charged with promoting greater trail use.

This study had two aims: (1) to describe and compare adult trail users and nonusers residing in a community with a rail-trail on demographics, physical activity, and barriers/perceived difficulty to using the trail; and (2) to further examine trail users by comparing patterns of use among men and women.

\section{Methods}

\section{Design and Sample}

This was a descriptive cross-sectional study of physical activity and trail use among adults living in Arlington, Massachusetts. The study protocol was approved by the ethics committee at the University of South Carolina School of Public Health. During the fall of 1998, a survey was mailed to 1002 adults, aged $18 \mathrm{y}$ and older, selected at random from a town census list. The survey methodology has been described previously. ${ }^{11}$ Four hundred nineteen adults returned a survey; the sample was reduced to 413 as the result of missing data.

\section{Measures}

The 53-item survey included questions on recreational physical activity, hypothesized correlates of activity based on an ecological model of health promotion, ${ }^{20} \mathrm{a}$ subset of questions for trail users, and two optional open-ended questions about use of the trail. Rail-trail use was determined with 1 question, which asked respon- 
dents whether they had used the Minuteman Bikeway, a 10.5 mi. paved rail-trail, at least once during the past $4 \mathrm{wk}$. Adults responding "yes" were categorized as bikeway users.

Respondents were asked to answer the following 2 items if they were currently doing recreational physical activity or exercise at any level (brisk walking, jogging/running, aerobic dancing, biking, swimming, rowing, in-line skating, weight lifting, or active sports) "During the past four weeks, how many days per week (on average) did you do recreational physical activity or exercise? (1-7 days)." "How many minutes (on average) did you exercise for each time?" Respondents were also asked about the types of activity they performed and the most common locations for these activities. The survey included 1 question on vigorous activity: "During a usual week, about how often do you do physical activity or exercise in your free time for at least 20 minutes without stopping, which is hard enough to make your heart rate and breathing increase a large amount?"

Two optional open-ended items related to use of the Minuteman Bikeway were included in the survey. The first item had 2 parts: "Please comment on how easy or difficult it is for you to get to the Minuteman Bikeway. If you do not use the Minuteman Bikeway, explain why you do not use it." The second item stated: "If you use the Bikeway, please comment on how easy or difficult it is for you to use it." The purpose of these items was twofold: (1) to gather qualitative data on barriers to trail use; and (2) to gain insights into users' perceptions of the trail, both positive and negative. Approximately 340 out of 413 respondents answered one or both of these items.

Finally, bikeway users were asked to answer 11 questions related to patterns of trail use: whether they used the trail for recreational physical activity or transportation, who they used the trail with most often, types of activity on the trail, frequency of use during the past $4 \mathrm{wk}$, length of time using the trail, perception of how much they would exercise if the bikeway were not available, usual mode of travel to the bikeway, how much of their walking, bicycling, etc. they perform on the trail, other locations where they engage in physical activity, the time of the week they use the bikeway, and seasons of the year when they use the trail $\geq 2$ times/wk.

\section{Statistical Analysis}

Descriptive statistics, including means ( \pm standard deviation) and frequencies, were used to summarize survey data. Demographic characteristics and physical activity data are presented for the overall sample and for bikeway users and nonusers. Frequencies were used to summarize patterns of trail use among all users and separately for men and women trail users. Chi-square statistics were used to examine differences between groups for categorical variables (or Fisher's exact test in cases where cell sizes were less than five). For continuous variables, we used two-sample $t$-tests to test for differences between groups. All analyses were performed with SAS software (version 8.1, SAS Institute Inc., Cary, NC).

\section{Results}

\section{Demographic Characteristics of Bikeway Users and Nonusers}

Overall, survey respondents lived a short distance from a trail access point: mean distance via the road network was $0.51 \mathrm{mi}$. (standard deviation $=0.28$ ) and the 
25th, 50th, and 75th percentiles were $0.28,0.47$ and $0.72 \mathrm{mi}$., respectively. Out of 413 survey respondents, $45.0 \%$ ( $n=186$ ) were identified as Minuteman Bikeway users. Compared to nonusers, bikeway users were significantly younger (55.9 \pm 17.7 and $45.5 \pm 13.6 \mathrm{y}$, respectively; $P=0.0001)$ and included a higher proportion of males (33.6\% and $46.8 \%$, respectively; $P=0.007)$. Ninety-five percent of bikeway users and $92 \%$ of nonusers were white. Over $60 \%$ of all respondents had at least a bachelor's degree and 30\% had a master's degree or higher. Twenty-six percent of nonusers had a high school degree or less, compared to about $10 \%$ of trail users $(P<0.0001)$. Just under $24 \%$ of nonusers reported a temporary or longterm physical activity limitation, whereas only about $14 \%$ of users reported these limitations $(P=0.01)$.

\section{Self-Reported Physical Activity for Trail Users and Nonusers}

As shown in Table 1, the majority of survey respondents reported recreational physical activity $\geq 3 \mathrm{~d} / \mathrm{wk}(61.5 \%)$. A higher proportion of Minuteman Bikeway users (79\%) compared to nonusers $(47 \%)$ reported being active $\geq 3 \mathrm{~d} / \mathrm{wk}$. Similar percentages of users and nonusers reported a frequency $<3 \mathrm{~d} / \mathrm{wk}$ and about a third of nonusers reported no recreational physical activity in the past $4 \mathrm{wk}$. A comparable proportion of active trail users ( $81 \%$ ) and active nonusers (78\%) engaged in $\geq 30 \mathrm{~min}$ of activity. Similar proportions of trail users $(70 \%)$ and nonusers $(61 \%)$ reporting any vigorous exercise $(n=231)$, performed $20 \mathrm{~min}, \geq 3 \mathrm{~d} / \mathrm{wk}(P=0.18)$.

As Table 1 indicates, bikeway users $(87.0 \%)$ and nonusers $(84.9 \%)$ reported walking was their most popular activity. Bikeway users reported bicycling (48.6\%) as the second most common activity, but bicycling was only reported by $3.4 \%$ of nonusers $(P<0.0001)$. Gardening was the second most common activity for nonusers and the third most common for trail users. Other significant differences between trail users and nonusers were for jogging/running (28\% and $8 \%$, respectively) and in-line skating (16\% and $0.7 \%$, respectively). The most frequently identified location for physical activity among bikeway users was the trail. High percentages of both users $(79.1 \%)$ and nonusers $(64.1 \%)$, however, reported that they used their neighborhood for physical activity $(P=0.003)$. A significantly greater proportion of nonusers compared to trail users reported being physically active at home (21\% and $11 \%$, respectively) and at a shopping mall (15\% and $7 \%$, respectively).

\section{Barriers and Concerns About Bikeway Use}

The reasons nonusers identified for not using the Minuteman Bikeway can broadly be categorized as individual (i.e., personal) or environmental factors (e.g., access). In descending order, the most frequently cited personal factors included a preference to engage in physical activity elsewhere (e.g., neighborhood), perception of the bikeway as a place to bicycle only, long-term disability, lack of time, older age, having young children, not physically active, bikeway is "boring," and lack of interest. As shown in Table 2, access barriers included distance to the bikeway and presence of hills; bikeway conditions included crowding on the trail and fast-moving bicyclists/in-line skaters; and safety concerns included presence of bicyclists and in-line skaters. Some respondents also felt unsafe on isolated areas along the trail. 
Table 1 Minuteman Bikeway Users and Nonusers' Frequency, Duration, Type, and Location of Recreational Physical Activity During the Previous 4 Weeks $(N=413)$

\begin{tabular}{lcccc}
\hline & $\begin{array}{c}\text { All survey } \\
\text { respondents } \\
\%(n)\end{array}$ & $\begin{array}{c}\text { Bikeway } \\
\text { users } \\
\%(n)\end{array}$ & $\begin{array}{c}\text { Nonusers } \\
\%(n)\end{array}$ & $P$-value \\
\hline Frequency* & & & & \\
0 times per week & $21.5(89)$ & $4.8(9)$ & $35.4(80)$ & $<0.0001$ \\
$<3$ times per week & $16.9(70)$ & $16.1(30)$ & $17.3(39)$ & \\
$\geq 3$ times per week & $61.5(254)$ & $79.0(147)$ & $47.4(107)$ & \\
Duration† & & & & \\
<30 min & $20.9(67)$ & $19.2(34)$ & $22.4(32)$ & 0.49 \\
$\geq 30$ min & $79.1(254)$ & $80.8(143)$ & $77.6(111)$ & \\
Outdoor activities $\ddagger$ & & & & \\
Walking & $86.1(279)$ & $87.0(154)$ & $84.9(124)$ & 0.59 \\
Gardening or yard work & $41.0(133)$ & $44.6(79$ & $36.3(53)$ & 0.13 \\
Outdoor bicycling & $28.1(91)$ & $48.6(86)$ & $3.4(5)$ & $<0.0001$ \\
Weight-lifting & $21.6(70)$ & $22.6(40)$ & $20.6(30)$ & 0.66 \\
Swimming & $19.8(64)$ & $22.6(40)$ & $15.8(23)$ & 0.12 \\
Jogging/running & $18.5(60)$ & $27.7(49)$ & $7.5(11)$ & $<0.0001$ \\
In-line skating & $9.0(29)$ & $15.8(28)$ & $0.7(1)$ & $<0.0001$ \\
Location§ & & & & \\
Neighborhood & $72.4(234)$ & $79.1(140)$ & $64.1(93)$ & 0.003 \\
Minuteman Bikeway & $51.4(166)$ & $89.3(158)$ & $5.5(8)$ & $<0.0001$ \\
Parks \& rec. facility & $22.6(73)$ & $23.7(42)$ & $20.7(30)$ & 0.51 \\
YMCA or fitness center & $20.4(66)$ & $21.5(38)$ & $18.6(27)$ & 0.53 \\
Home & $15.4(50)$ & $11.3(20)$ & $20.6(30)$ & 0.02 \\
Outdoor recreation area & $11.7(38)$ & $14.1(25)$ & $8.9(13)$ & 0.15 \\
Shopping mall & $10.5(34)$ & $7.3(13)$ & $14.5(21)$ & 0.04 \\
\hline
\end{tabular}

Note. * Frequency item: During the past four weeks, how many days per week (on average) did you do recreational physical activity or exercise? (1-7 days) (Examples of recreational physical activity or exercise are brisk walking, jogging or running, aerobic dancing, biking, swimming, rowing, in-line skating, weight-lifting, or active sports which you do during your free time for recreational or fitness purposes).

$\dagger$ Duration item: How many min (on average) did you exercise for each time?

$\ddagger$ Respondents were instructed to "check all that apply." Data are not shown, but there were no statistically significant differences in the proportion of trail users and nonusers performing stationary bicycling, active sports, aerobic dance, or using an indoor stair climbing machine.

$\S$ Respondents were instructed to "check all that apply." Parks $\&$ rec. facility $=$ parks $\&$ recreation facility.

Overall, bikeway users' comments about the bikeway were positive, including that it was "easy to use," a "wonderful community resource," and that it is well maintained. As shown in Table 2, some users reported access issues including crossing busy streets and lack of parking; trail conditions, including "too many" bicyclists and in-line skaters, and crowding at certain times; and safety concerns 
Table 2 Survey Respondents' Perceived Environmental Barriers and Concerns About Using the Minuteman Bikeway: Compiled from Open-Ended Survey Questions

\begin{tabular}{lcc}
\hline Environmental barrier/concern & Nonusers & Bikeway users \\
\hline Access to bikeway & & - \\
Distance or time to get to the trail & $\checkmark$ & $\checkmark$ \\
Hills & $\checkmark$ & $\checkmark$ \\
Busy streets to cross & $\checkmark$ & $\checkmark$ \\
Lack of parking/parking is difficult & $\checkmark$ & $\checkmark$ \\
Conditions on bikeway & - & $\checkmark$ \\
Crowding or congestion & - & $\checkmark$ \\
Bicyclists/in-line skaters ("too many") & - & \\
Lack of lighting & & \\
Needs maintenance/repairs & & \\
Pavement is not smooth enough (e.g., for in-line skaters) \\
Needs more signage (e.g., trail rules, for vehicles at \\
$\quad$ intersections) \\
Perceived safety \\
Lack of safety due to bicyclists/in-line skaters or \\
$\quad$ congestion \\
Isolated/secluded \\
Lack of courtesy/consideration/users don't follow rules
\end{tabular}

Note. Nonusers: Less frequent comments: do other kind of physical activity; only use at certain times of year; easier to walk in neighborhood; need stairs at access point; dog droppings; trail crosses busy streets; not scenic; safety in general; fear of others, such as teenagers. Users: Less frequent comments: it's safe; hazardous with young children, especially on weekends; entrances/access points are hazardous [e.g., narrow passage for bikes]; less noise and traffic, no trucks/buses, and well-paved; flat or easy grades; impediment to bike commuting is lack of showers at work.

including fast-moving bicyclists and in-line skaters. Some trail users also indicated the need for better maintenance and repairs (e.g., repaving), dangerous or busy street crossings, and the need for improved signage for cars and trail users.

\section{Patterns of Trail Use for Men and Women}

Patterns of trail use among the 186 women and men who reported using the Minuteman Bikeway at least $1 \mathrm{~d}$ during the previous month are shown in Table 3. Men and women did not differ as to frequency of visits during the previous 4-wk period (7.2 $\pm 5.9 \mathrm{~d}$ and $7.4 \pm 6.2 \mathrm{~d}$, respectively; $P=0.84$ ), nor the proportions using the trail for exercise, transportation, or a combination of the two. Similar proportions of men and women used the trail by themselves; however, more women than men used the trail with friends (29\% and $11 \%$, respectively $[P=0.003])$. Significantly more women $(91 \%)$ compared to men $(66 \%)$ reported walking on the trail $(P<$ $0.0001)$. More women (79\%) than men (55\%) traveled to the trail by walking $(P$ $=0.0007)$, whereas, similar percentages of men and women drove (30\% and $20 \%$, respectively $[P=0.14])$. 
Table 3 Selected Patterns of Rail-Trail Use for Men and Women Using the Minuteman Bikeway, Fall 1998

\begin{tabular}{|c|c|c|c|c|}
\hline Trail use variables & $\begin{array}{l}\text { All trail } \\
\text { users } \\
\%(n)\end{array}$ & $\begin{array}{l}\text { Women } \\
\%(n)\end{array}$ & $\begin{array}{l}\text { Men } \\
\%(n)\end{array}$ & $P$-value \\
\hline \multicolumn{5}{|l|}{ Reason person uses bikeway } \\
\hline Exercise & $63.7(116)$ & $66.0(64)$ & $61.2(52)$ & 0.33 \\
\hline Transportation & $5.5(10)$ & $3.1(3)$ & $8.2(7)$ & \\
\hline Exercise \& transportation & $30.8(56)$ & $30.9(30)$ & $30.6(26)$ & \\
\hline \multicolumn{5}{|l|}{ Person uses bikeway with* } \\
\hline Self only & $68.3(125)$ & $65.3(64)$ & $71.8(61)$ & 0.35 \\
\hline Family & $50.3(92)$ & $52.0(51)$ & $48.2(41)$ & 0.61 \\
\hline Friends & $20.8(38)$ & $28.6(28)$ & $10.6(9)$ & 0.003 \\
\hline Pet & $3.3(6)$ & $4.1(4)$ & $2.4(2)$ & 0.69 \\
\hline \multicolumn{5}{|l|}{$\begin{array}{l}\text { Type of physical activity person on } \\
\text { bikeway } \dagger\end{array}$} \\
\hline Walk & $78.9(146)$ & $90.8(89)$ & $65.5(57)$ & $<0.0001$ \\
\hline Jog/run & $28.6(53)$ & $30.6(30)$ & $26.4(23)$ & 0.53 \\
\hline Bicycle & $57.3(106)$ & $51.0(50)$ & $64.4(56)$ & 0.07 \\
\hline In-line skating & $21.6(40)$ & $22.5(22)$ & $20.7(18)$ & 0.77 \\
\hline \multicolumn{5}{|l|}{ Mode of transportation to bikeway* } \\
\hline Motorized vehicle (e.g., car) & $24.9(46)$ & $20.4(20)$ & $29.9(26)$ & 0.14 \\
\hline Walk & $67.6(125)$ & $78.6(77)$ & $55.2(48)$ & 0.0007 \\
\hline Jog/run & $10.8(20)$ & $8.2(8)$ & $13.8(12)$ & 0.22 \\
\hline Bicycle & $35.7(66)$ & $32.7(32)$ & $39.1(34)$ & 0.36 \\
\hline \multicolumn{5}{|l|}{$\begin{array}{l}\text { Proportion of physical activity person } \\
\text { does on bikeway } \ddagger\end{array}$} \\
\hline All or most of it & $51.9(96)$ & $49.0(48)$ & $55.2(48)$ & 0.40 \\
\hline Some or very little of it & $48.1(89)$ & $51.0(50)$ & $44.8(39)$ & \\
\hline \multicolumn{5}{|l|}{$\begin{array}{l}\text { How often person would do physical } \\
\text { activity if bikeway not available } \neq\end{array}$} \\
\hline Just as often & $41.8(77)$ & $36.1(35)$ & $48.3(42)$ & 0.04 \\
\hline Somewhat less often & $33.7(62)$ & $32.0(31)$ & $35.6(31)$ & \\
\hline $\begin{array}{l}\text { Much less often or very rarely/not } \\
\text { at all }\end{array}$ & $24.4(45)$ & $32.0(31)$ & $16.1(14)$ & \\
\hline \multicolumn{5}{|l|}{ Length of time person used bikeway } \\
\hline$\leq 1$ year & $18.6(34)$ & $16.5(16)$ & $20.9(18)$ & 0.44 \\
\hline$>1$ year & $81.4(149)$ & $83.5(81)$ & $79.1(68)$ & \\
\hline \multicolumn{5}{|l|}{ Time of week person used bikeway } \\
\hline Weekdays & $22.4(41)$ & $22.7(22)$ & $22.1(19)$ & 0.39 \\
\hline Weekend & $18.0(33)$ & $14.4(14)$ & $22.1(19)$ & \\
\hline Both weekdays \& weekends & $59.6(109)$ & $62.9(61)$ & $55.8(48)$ & \\
\hline
\end{tabular}


Table 3 (continued)

\begin{tabular}{lcccc}
\hline & $\begin{array}{c}\text { All trail } \\
\text { users } \\
\%(n)\end{array}$ & $\begin{array}{c}\text { Women } \\
\%(n)\end{array}$ & $\begin{array}{c}\text { Men } \\
\%(n)\end{array}$ & $P$-value \\
Trail use variables & & & & \\
\hline $\begin{array}{l}\text { Other locations where person does } \\
\text { physical activity } \S\end{array}$ & & & & \\
$\quad$ Sidewalk & $72.0(121)$ & $80.9(72)$ & $62.7(47)$ & 0.009 \\
Road & $53.6(90)$ & $47.2(42)$ & $62.7(47)$ & 0.05 \\
Another trail & $23.8(40)$ & $22.5(20)$ & $26.7(20)$ & 0.53 \\
Outdoor school track & $6.5(11)$ & $5.6(5)$ & $8.0(6)$ & 0.54 \\
YMCA or health club & $13.7(23)$ & $16.9(15)$ & $10.7(8)$ & 0.26 \\
Shopping mall & $10.7(18)$ & $14.6(13)$ & $5.3(4)$ & 0.07 \\
Parks \& recreation facility & $22.6(38)$ & $22.5(20)$ & $24.0(18)$ & 0.82 \\
\hline
\end{tabular}

Note. * Respondent could select up to two of the most frequent categories.

$\dagger$ Respondent asked to check "all that apply."

$\ddagger$ Physical activity refers to walking, jogging, running, bicycling, or in-line skating.

$\S$ Question excluded respondents who reported performing all of their physical activity on the bikeway.

As shown in Table 3, men and women reported similar proportions of activity performed on the trail. About $12 \%$ more women than men reported that their frequency of activity would be negatively affected if the bikeway were not available $(P=0.04)$. Most women and men reported using the rail-trail for more than $1 \mathrm{y}$. Compared to male bikeway users, female users were more likely to use sidewalks (80.9\% and $62.7 \%$, respectively) and male trail users were more likely to use a road as another location for physical activity (63\% and $47 \%$, respectively).

\section{Discussion}

To our knowledge, this is the first physical activity study to both compare trail users and nonusers residing in a particular community and to examine gender differences in trail use patterns. The proportion of rail-trail users in our suburban sample (45\%) was comparable to the percentage of adults living in rural counties in Missouri with access to walking trails who reported using these facilities (39\%). ${ }^{12}$ As we reported earlier, ${ }^{11}$ trail users in our study were more likely to be younger and male in comparison to nonusers. A recent study of a $16.5 \mathrm{~km}$ rail-trail in western Sydney, Australia, also found that trail users tended to be male and from younger age groups. ${ }^{10}$ Brownson and colleagues, however, found that among those with access to walking paths, women were more likely to use these facilities than men. ${ }^{12}$ A plausible explanation for these disparate findings is that men and women have different activity preferences and that the specific design characteristics of trails/ paths determine the types of activity that can be supported. For example, the trails in the Brownson study were relatively short, varying from 0.13 to $2.38 \mathrm{mi}$., located in residential parks, and over half had a gravel or wood chip surface. ${ }^{12}$ These are all characteristics that would tend to support walking over bicycling. Alternatively, 
rail-trails, such as the Minuteman Bikeway, are linear, often paved, and tend to be relatively long; characteristics that might attract more cyclists.

We found that a higher percentage of nonusers had less than a high school education. Other trail studies both in public health ${ }^{12}$ and nonpublic health disciplines ${ }^{14,16,17}$ have shown that trail users tend to be higher educated and have higher incomes. For example, Lindsey ${ }^{14}$ reported that the adults he surveyed on three greenway trails in Indianapolis were higher educated. Because of the disproportionate use of trails by those with higher education, some have called for a closer examination of "sociocultural equity" on urban trails. ${ }^{17}$

In our study, rail-trail users and nonusers differed on some physical activity parameters; however, on others the 2 groups were similar. Overall, trail users appeared more active, reporting a higher frequency of recreational physical activity. This is generally consistent with the study of rural walking trails, which found that users were more likely to be regular walkers ( 5 times/wk for $30 \mathrm{~min}$ or more). ${ }^{12}$ Among our respondents reporting any vigorous exercise, however, only about $9 \%$ more trail users met the recommended level of vigorous activity (i.e., $20 \mathrm{~min}, \geq$ 3 times/wk) than nonusers. This suggests that there is a group of nontrail users that is quite active, but uses resources other than the Minuteman Bikeway.

We found that walking was the most popular activity for both trail users and nonusers. The second most common activities for users and nonusers, however, were cycling and gardening/yard work, respectively. A high percentage of both users and nonusers indicated that their neighborhood was a common location for physical activity. This suggests that for many adults, particularly those who walk, pedestrian facilities such as well-maintained sidewalks, are an important environmental support.

Nonusers identified a variety of individual-level factors and environmental barriers to using the bikeway. Of note, both nonusers and users reported some shared environmental concerns related to accessing the bikeway (e.g., busy streets), adverse conditions on the bikeway such as crowding, and concerns about safety related to other rail-trail users' behavior. The commonalities we found in types of activity preferred (walking), locations for activity (neighborhood), and environmental concerns, indicate the need for further qualitative research to determine the behavior settings in which different individuals prefer being physically active. For example, why do certain environmental attributes, such as a busy street to cross, serve as a barrier for nonusers, but merely an apparent nuisance for trail users?

There has been little research examining gender differences among adults using community trails and paths. An exception was the Missouri study noted previously, which found that women using walking paths were about twice as likely as men to report an increase in their walking since they began using these facilities. ${ }^{12}$ Similarly, a higher percentage of women trail users in our study indicated that their physical activity (i.e., walking, other linear activities) would decrease if the bikeway were not available, as compared to men. It is not clear why women and men bikeway users differed in their perception of how the trail supports their physical activity; again qualitative studies might help to shed light on this difference.

The three other primary differences we observed between women and men bikeway users were that a higher percentage of women used the trail with friends, more women reported walking as their most common activity on the trail, and more women reported walking as a mode of travel to the trail. These 
findings might be useful both from the perspective of promoting trail use in communities and designing trails that will attract a wide cross-section of the population. While family social support could be important for men and women, availability of a friend to use the trail with appears more important for women. Overall, social support strategies might be more effective in promoting trail use among women, which is consistent with previous research showing that social support is an important positive influence on women's physical activity. ${ }^{21}$ From a physical activity promotion standpoint, it is important to design and build trails that fit into the preferred activities of both men and women-which in our case appears to be cycling and walking, respectively. Multi-use rail-trails can often meet both needs, but it is likely that many walkers prefer to use trails/paths that exclude cyclists.

Neighborhood contextual factors, such as population and residential density, street connectivity, racial/ethnic composition, and socioeconomic status, could mediate or moderate patterns of trail use in various communities. Arlington, although suburban, is densely populated and most trail users lived relatively close to the trail. Thus, about two-thirds of trail users reported walking as a mode of travel to the trail. Further research should not only consider individual users' characteristics, but neighborhood-level factors such as connectivity of road networks that might positively or negatively influence use.

Our study has several limitations. First, our findings cannot be generalized to urban or rural communities or to trails or communities with more sociodemographic diversity (i.e., our sample was predominantly white). In addition to the Minuteman Bikeway, the town of Arlington appears to have neighborhoods with sidewalks and aesthetic features that support walking. Depending on the physical characteristics of neighborhoods in which trails are located, these facilities could play a larger or smaller role in supporting physical activities such as walking and bicycling. The relative contribution of trails to physical activity in different settings warrants further study. Similarly, our examination of only 1 trail in a single community in 1 region of the country is another limitation. Patterns of trail use, such as frequency of visits and types of physical activity, vary greatly among rail-trails located in more densely populated suburban communities and rural areas ${ }^{16}$ Nevertheless, it is interesting to note that sociodemographic characteristics of Minuteman Bikeway users were comparable to users in Indiana ${ }^{14}$ and Texas ${ }^{17}$ — two distinctly different states. There is likely some response bias in our sample. We expect that more active trail users (versus inactive, nonusers) were more likely to complete a survey. Because we did not geocode addresses of nonrespondents, we are not able to determine whether there is bias in the geographic representativeness of our sample. Maps we produced in a previous study, however, indicate that survey respondents were distributed throughout Arlington.

\section{Acknowledgments}

This study was supported by a grant from the Massachusetts Governor's Committee on Physical Fitness and Sports and in-kind support from the Massachusetts Department of Public Health and the Arlington Planning and Community Development Department. 


\section{References}

1. US Dept of Health and Human Services. Physical activity and health: a report of the Surgeon General. Atlanta, GA: US Dept of Health and Human Services, Centers for Disease Control and Prevention, National Center for Chronic Disease Prevention and Health Promotion; 1996.

2. US Dept of Health and Human Services. Healthy People 2010. (Conference edition in 2 volumes). Washington, DC: US Dept of Health and Human Services; 2000.

3. King AC, Jeffery RW, Fridinger F, et al. Environmental and policy approaches to cardiovascular disease prevention through physical activity: issues and opportunities. Health Educ Q. 1995;22(4):499-511.

4. Schmid TL, Pratt M, Howze E. Policy as intervention: environmental and policy approaches to the prevention of cardiovascular disease. Am J Public Health. 1995;85(9): 1207-1211.

5. Sallis JF, Bauman A, Pratt M. Environmental and policy interventions to promote physical activity. Am J Prev Med. 1998;15(4):379-397.

6. Kahn EB, Ramsey LT, Brownson RC, et al. The effectiveness of interventions to increase physical activity. A systematic review. Am J Prev Med. 2002;22(4 suppl): 73-107.

7. Humpel N, Owen N, Leslie E. Environmental factors associated with adults' participation in physical activity: a review. Am J Prev Med. 2002;22(3):188-199.

8. Saelens BE, Sallis JF, Frank LD. Environmental correlates of walking and cycling: findings from the transportation, urban design, and planning literatures. Ann Behav Med. 2003;25(2):80-91.

9. Neff LJ, Ainsworth BE, Wheeler FC, Krumwiede SE, Trepal AJ. Assessment of trail use in a community park. Fam \& Community Health. 2000;23(3):76-84.

10. Merom D, Bauman A, Vita P, Close G. An environmental intervention to promote walking and cycling - the impact of a newly constructed Rail Trail in Western Sydney. Prev Med. 2003;36(2):235-242.

11. Troped PJ, Saunders RP, Pate RR, Reininger B, Ureda JR, Thompson SJ. Associations between self-reported and objective physical environmental factors and use of a community rail-trail. Prev Med. 2001;32(2):191-200.

12. Brownson RC, Housemann RA, Brown DR, et al. Promoting physical activity in rural communities: walking trail access, use, and effects. Am J Prev Med. 2000;18(3):235241.

13. Wang G, Macera CA, Scudder-Soucie B, Schmid T, Pratt M, Buchner D. Cost effectiveness of a bicycle/pedestrian trail development in health promotion. Prev Med. 2004;38(2):237-242.

14. Lindsey G. Use of urban greenways: insights from Indianapolis. Landscape \& Urb Plann. 1999;45:145-157.

15. Gobster PH. Perception and use of a metropolitan greenway system for recreation. Landscape \& Urb Plann. 1995;33:401-413.

16. Moore RL, Graefe AR, Gittelson R, Porter B. The impact of rail-trails. A study of user and property owners from three rail-trails. Washington, DC: National Park Service; 1992.

17. Shafer CS, Lee BK, Turner S. A tale of three greenway trails: user perceptions related to quality of life. Landscape \& Urb Plann. 2000;49:163-178. 
18. Wolter SA, Lindsey G. Summary Report Indiana Trails Study. A study of trails in 6 Indiana cities.: Eppley Institute for Parks and Public Lands, Center for Urban Policy and the Environment; 2001.

19. Lindsey G, Nguyen D. Use of urban greenway trails in Indiana. J Urb Plann and Dev. 2004; 30(4):213-217.

20. McLeroy KR, Bibeau D, Steckler A, Glanz K. An ecological perspective on health promotion programs. Health Educ Q.1988;15(4):351-377.

21. Eyler AA, Brownson RC, Donatelle RJ, King AC, Brown D, Sallis JF. Physical activity social support and middle- and older-aged minority women: results from a US survey. Soc Sci Med. 1999;49(6):781-789. 